\title{
Assessing the sources of high fecal coliform levels at an urban tropical beach
}

\author{
Aline Mendonça Cavalcante Davino, Milena Bandeira de Melo, \\ Roberto Augusto Caffaro Filho
}

Centro de Tecnologia, Universidade Federal de Alagoas, Maceió, AL, Brazil.

Submitted: May 30, 2014; Approved: February 10, 2015.

\begin{abstract}
Recreational water quality is commonly assessed by microbial indicators such as fecal coliforms. Maceió is the capital of Alagoas state, located in tropical northeastern Brazil. Its beaches are considered as the most beautiful urban beaches in the country. Jatiúca Beach in Maceió was found to be unsuitable for bathing continuously during the year of 2011. The same level of contamination was not observed in surrounding beaches. The aim of this study was to initiate the search for the sources of these high coliform levels, so that contamination can be eventually mitigated. We performed a retrospective analysis of historical results of fecal coliform concentrations from 2006 to 2012 at five monitoring stations located in the study region. Results showed that Jatiúca Beach consistently presented the worst quality among the studied beaches. A field survey was conducted to identify existing point and non-point sources of pollution in the area. Monitoring in the vicinity of Jatiúca was spatially intensified. Fecal coliform concentrations were categorized according to tide range and tide stage. A storm drain located in northern Jatiúca was identified as the main point source of the contamination. However, fecal coliform concentrations at Jatiúca were high during high tides and spring tides even when this point source was inactive (no rainfall). We hypothesize that high fecal coliform levels in Jatiúca Beach may also be caused by aquifer contamination or, more likely, from tide washing of contaminated sand. Both of these hypotheses will be further investigated.
\end{abstract}

Key words: recreational water quality, fecal indicators, coastal pollution.

\section{Introduction}

The exposure to microbial pathogens can result in swimming-related illness. Each year, millions of cases of gastrointestinal diseases are caused by swimming and bathing in wastewater-polluted coastal waters (Shuval, 2003). Pathogens enter the water through point sources such as sewage outfalls. Water quality at beaches may also be affected by non-point sources, such as storm water runoff, sand resuspension, animal fecal inputs, and human bather shedding (Abdelzaher et al., 2010).

Waterborne pathogens often occur at low concentrations and their detection can be difficult. Fecal Indicator Bacteria (FIB) is a group of microorganisms of the comensal flora of the gut used to indicate the potential occurrence of pathogens in water. This group includes Escherichia coli, enterococci, clostridia, etc. FIB are generally more abundant and easily measured than fecal pathogens (Edge and Boehm, 2011).

Fecal Coliforms (FC) are a group of FIB used to assess recreational water quality throughout the world. CONAMA 274/00 Resolution defines the criteria for recreational water quality in Brazil, including monitoring methodology, microbiological indicators and reference concentrations that classify water as suitable or unsuitable for bathing activities. Regarding the concentrations of FC, Brazilian recreational waters are considered unsuitable when they exceed 2,500 cfu or MPN/100 mL, or exceed $1,000 \mathrm{cfu}$ or MPN $/ 100 \mathrm{~mL}$ in more than $20 \%$ of the samples collected in a five-week monitoring period.

Tourism accounts for a large part of income generation in the state capitals of the Brazilian northeast region, which has a tropical climate. Maceió is the capital of Alagoas state, and its beaches are considered the most beautiful 
urban beaches in Brazil. Beach water quality in Maceió is monitored weekly by the state environmental agency. According to official data, Jatiúca Beach, one of the main tourist hubs of Alagoas, showed unsuitable condition for bathing continuously throughout the year of 2011. During this period, the same level of contamination was not observed in surrounding beaches, namely Ponta Verde and Cruz das Almas. The reasons for this exceptional contamination at Jatiúca Beach are unknown. The aim of this study was to initiate the search for the sources of high coliform levels in Jatiúca Beach, so that this contamination can be eventually mitigated.

\section{Materials and Methods}

\section{Site description}

Jatiúca Beach has a densely urbanized waterfront, with dozens of hotels and hostels, as well as bars, restaurants and shops. The surrounding beaches of Ponta Verde (south) and Cruz das Almas (north) have similar characteristics. In this coastal region, shown in Figure 1, there are five monitoring stations for recreational water quality,

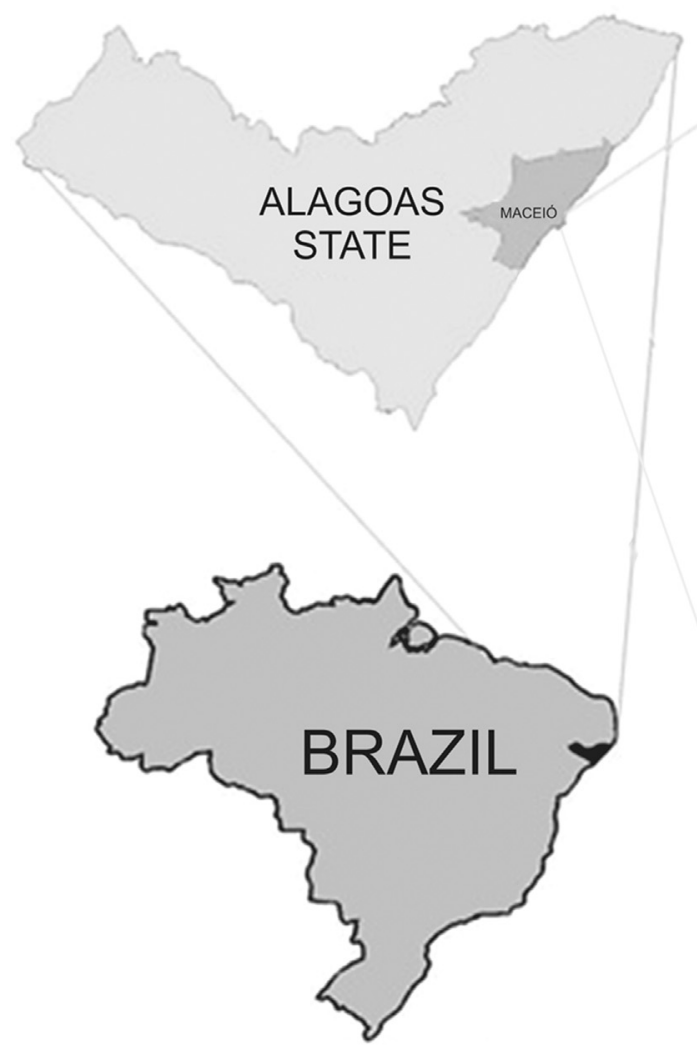

which are sampled weekly by the state environmental agency.

\section{Historical monitoring data analysis}

A retrospective analysis of historical data of fecal coliform (FC) concentrations obtained from 2006 to 2012 at the five monitoring stations located in the study site was performed. According to the methodology proposed by Boehm et al. (2002), the results of each year were categorized into wet season (obtained in the months of May, June and July - MJJ) and dry season (obtained in the months of November, December and January of the following year NDJ). Geometric means and confidence intervals (95\%) were calculated for each category (e.g., 2006 MJJ; 2006 NDJ; etc.). Concentrations of FC, date and time of each sampling were obtained from the state environmental agency. The accumulated rainfall data were obtained from the state agency responsible for rainfall monitoring.

\section{Study of the surroundings of JTC monitoring station}

Due to recurrent high levels of FC observed in 2011, the state environmental agency temporarily increased the

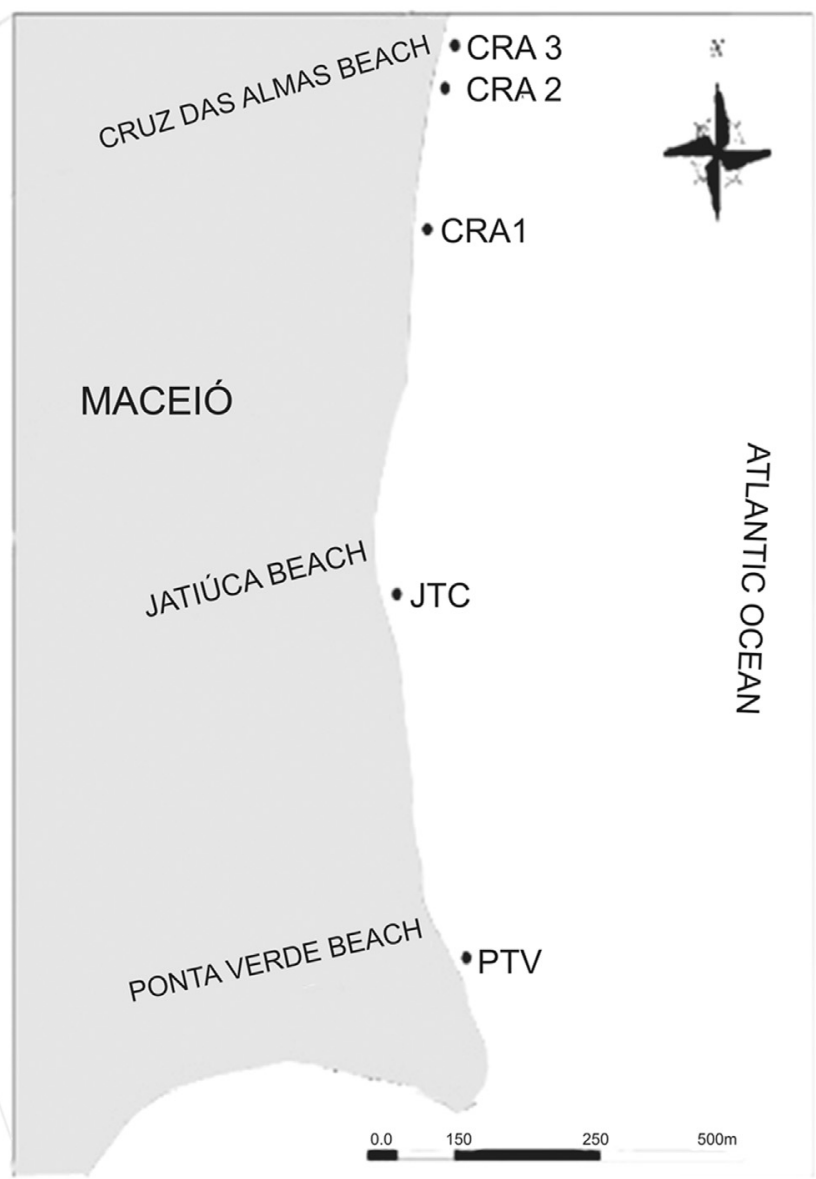

Figure 1 - Study area, located in a densely urbanized coastal region in the city of Maceió, capital of Alagoas state, northeastern Brazil. In the figure, on the right side, the location of the five existing monitoring stations is shown: one at Praia da Ponta Verde (PTV), one at Jatiúca Beach (JTC) and three at Cruz das Almas Beach (CRA 1, CRA 2 and CRA 3). 
monitoring mesh surrounding JTC monitoring station, adding a station 100 meters south (JTC S) and 100 meters north (JTC N) of station JTC. FC concentrations at these stations and also at stations on adjacent beaches (PTV and CRA 1) were evaluated between August and December 2012. For each station, the geometric mean and confidence intervals ( $95 \%$ ) of FC concentrations were calculated. FC concentrations in each monitoring station were also categorized according to tide range (spring/neap, based on lunar cycle) and tide stage $(\geq 1 \mathrm{~m}=$ high and $<1 \mathrm{~m}=$ low $)$ at sampling. Geometric means and confidence intervals (95\%) were calculated for each category at each monitoring station.

\section{Results and Discussion}

\section{Retrospective evaluation of water quality}

Figure 2 shows the geometric means of FC concentrations observed between years 2006 and 2012, during wet (MJJ) and dry seasons (NDJ), at monitoring stations PTV, JTC, CRA 1, CRA 2 and CRA 3 collectively and individu-
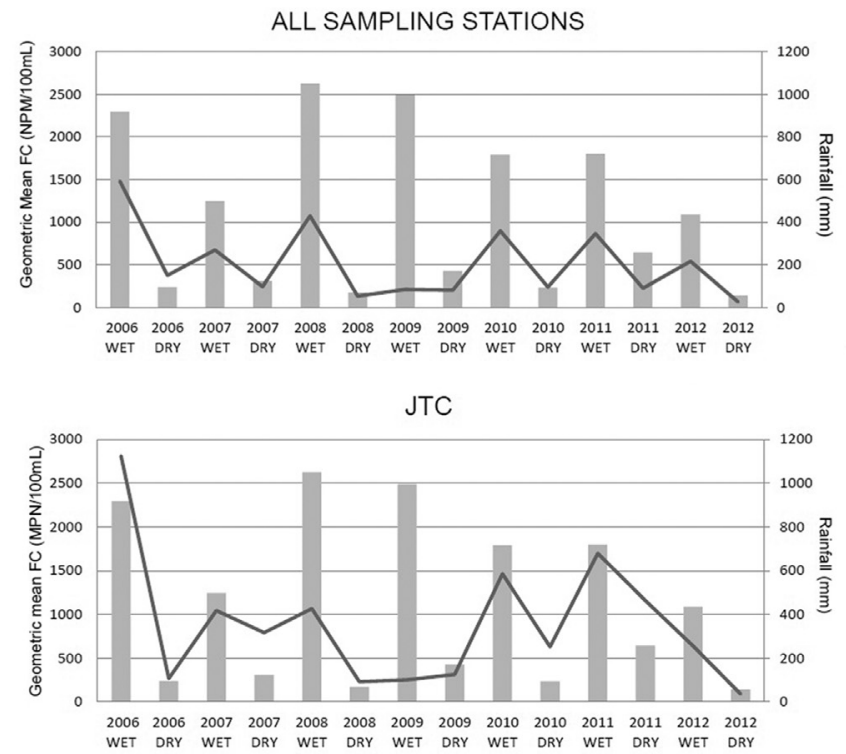

CRA 2

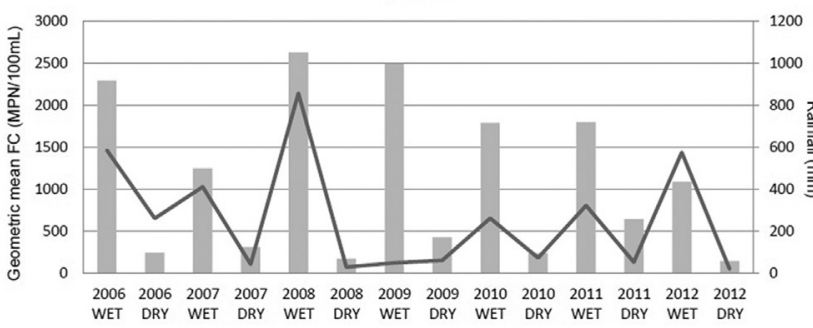

ally. Total rainfall in each season can also be seen in the same figure.

As expected, geometric means during wet seasons were always higher than geometric means of dry seasons. The same was observed by Boehm et al. (2002), when they evaluated, in a similar manner, the variability of microbial indicator concentrations in a southern California beach for a period of 43 years. The rainy season of 2009 was an exception to this rule. We believe that this was due to systematic analytical or sample processing errors, which were corrected by the agency after this short period.

Between 2010 and 2012, we note that JTC station (Jatiúca Beach) showed higher geometric means when compared to the means of all other monitoring stations taken together (upper left corner). This becomes more evident, if we consider only the dry season of 2011, when the geometric mean at JTC was greater than 1,000 MPN/100 mL.

Since the pollution signal is indiscriminately high during wet seasons, we grouped the geometric means (in
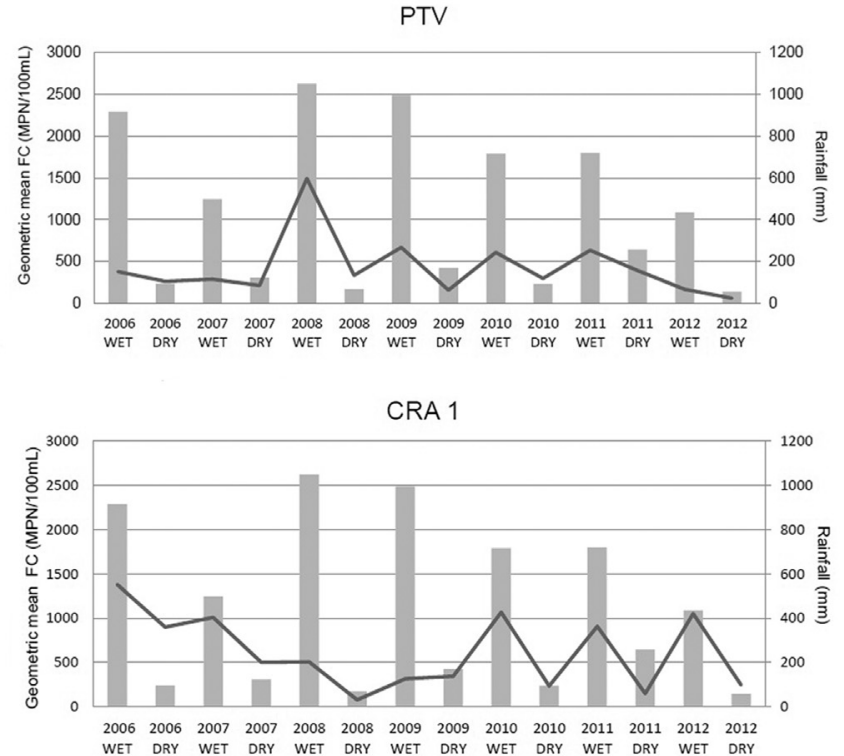

CRA 3

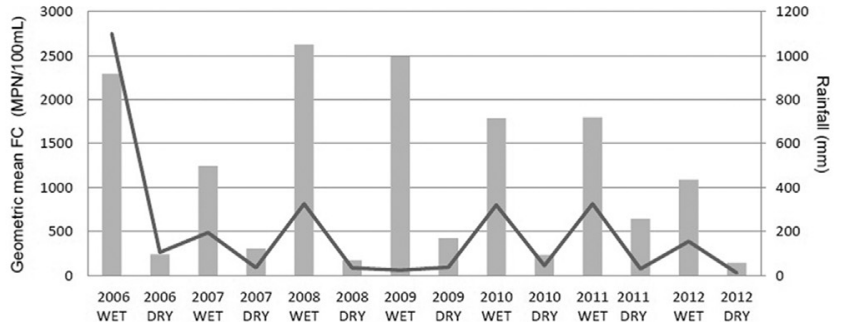

Figure 2 - Geometric means of FC concentrations (lines) observed between the years 2006 and 2012, during wet (MJJ) and dry seasons (NDJ), at monitoring stations PTV, JTC, CRA 1, CRA 2 and CRA 3, collectively (all monitoring stations) and individually. Total rainfall in each season is represented by bars. This graph summarizes results from $841 \mathrm{FC}$ analyses. 
logarithmic scale) for the monitoring stations considering only the dry season of each year, as shown in Figure 3.

During dry seasons, the log geometric mean of FC while considering all monitoring stations collectively (top left) fell between 2 and 2.5, throughout the study period. However, JTC station showed higher log geometric means of FC, between 2.5 and 3. Thus, Jatiúca Beach consistently presented the worst quality among all the beaches considered in this research.

For year 2012, we can see a significant improvement in overall quality of surveyed stations. We attribute it to the atypical low rainfall observed in that year, even during the wet season.

\section{Spatial intensification of monitoring around Jatiúca Beach}

In order to assess the cause of the high levels of FC in Jatiúca Beach a field survey was conducted to identify existing point and non-point sources of pollution in the area. Also, monitoring in the vicinity of station JTC was spatially intensified. Two new stations, Jatiúca north (JTC N) and
Jatiúca south (JTC S) were added to the monitoring grid and sampled weekly for approximately 4 months between August and December 2012.

The coastal discharges found in the study region are shown in Figure 4. Altogether, 6 storm drains and a stream that can directly influence water quality were identified. In Figure 4, the geometric means of FC for the monitoring stations sampled between August and December 2012 are also presented. The pollution signal was greater north of JTC monitoring station, near station JTC-N.

Northeastern wind prevails during the months of September to December in Maceió, generating currents in the north-south direction. Considering this characteristic and on the basis of the field survey, we identified a storm drain slightly north of the station JTC-N as the main point source of fecal contamination in Jatiúca Beach (storm drain $1 /$ Figure 4).

Contaminated water discharge into the sea through storm drains has been observed in some studies in other capitals of the northeast region of Brazil. High FC concentrations $\left(10^{6}-10^{7}\right)$ were found in storm drains of Fortaleza
ALL SAMPLING STATIONS

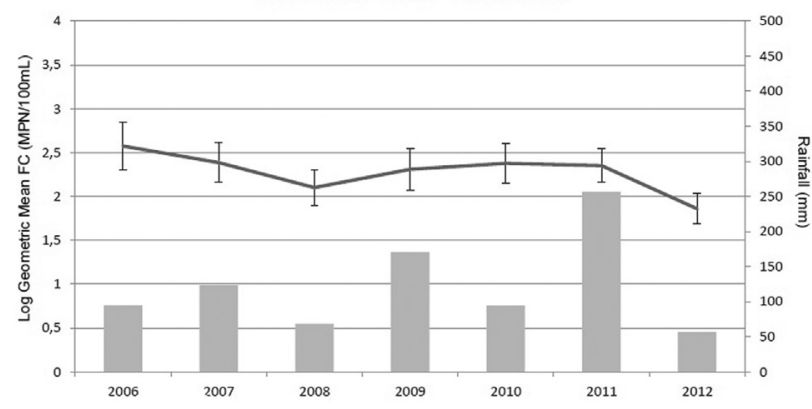

JTC

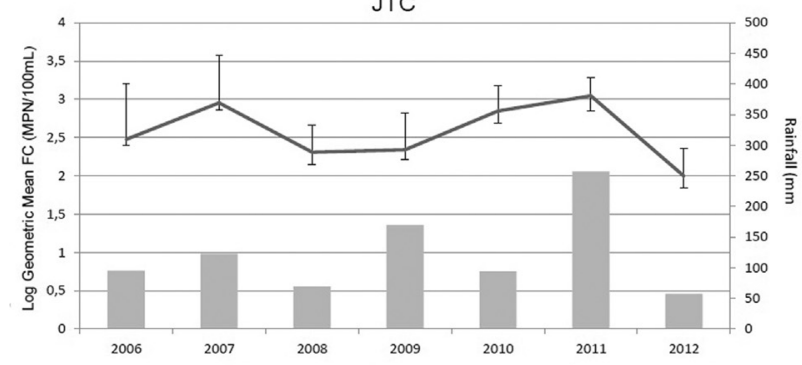

CRA 2

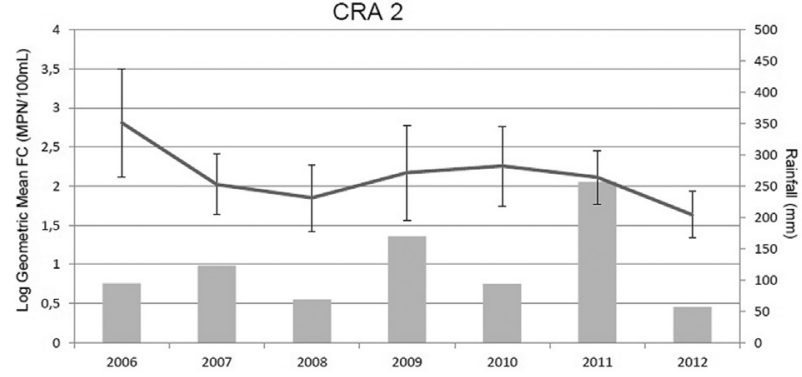

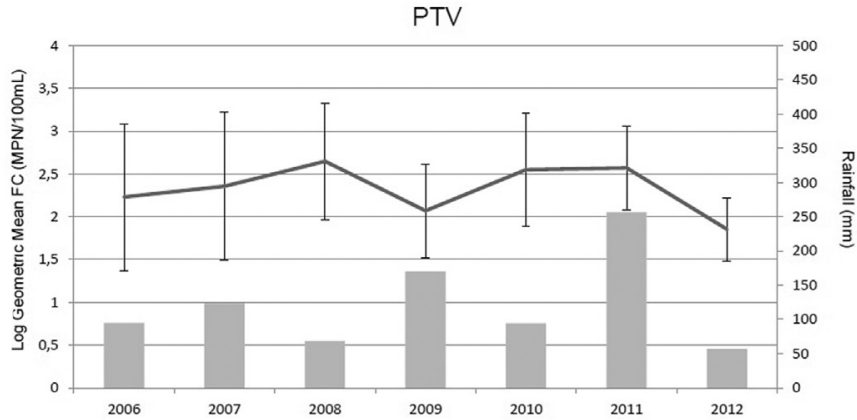

CRA 1

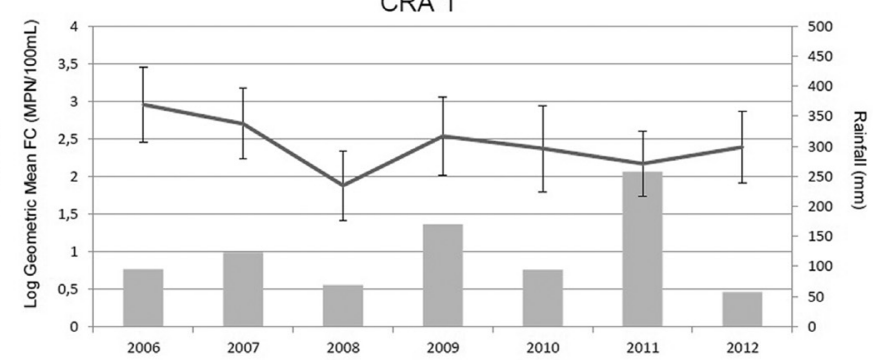

CRA 3

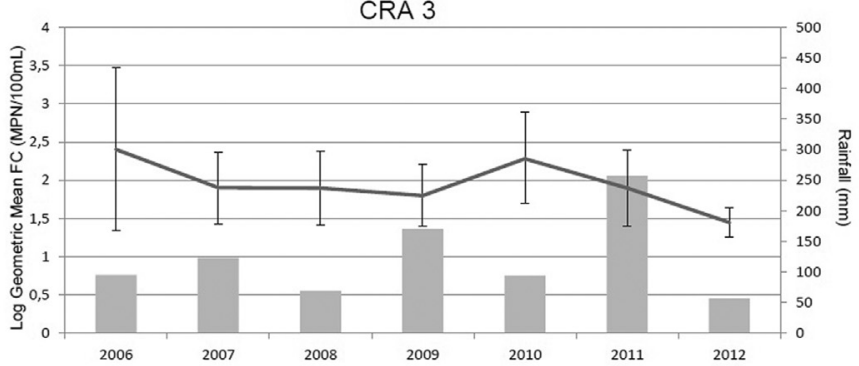

Figure 3 - Geometric means (lines) in logarithmic scale and confidence intervals (95\%) of FC concentrations observed between 2006 and 2012, during dry seasons (NDJ), at monitoring stations PTV, JTC, CRA 1, CRA 2 and CRA 3, collectively (all monitoring stations) and individually. Total rainfall in each season is represented by bars. This graph summarizes results from $406 \mathrm{FC}$ analyses. 


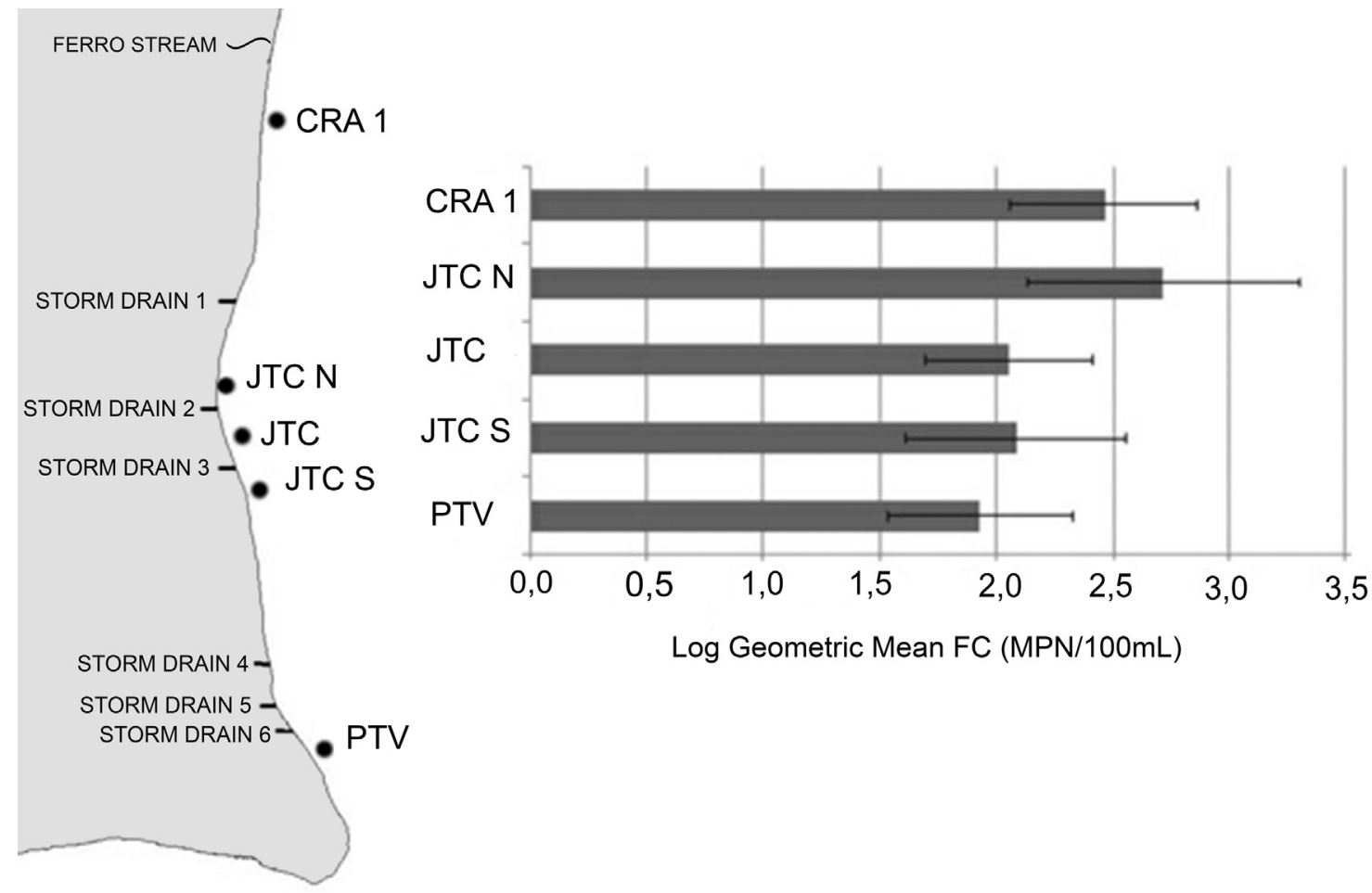

Figure 4 - Coastal discharges found in the study region and geometric means of FC with confidence intervals (95\%) for monitoring stations PTV, JTC and CRA 1, plus additional stations 100 meters south (JTC S) and north (JTC N) of JTC station. This chart summarizes 85 samples collected between August and December 2012.

and Natal and attributed to contamination by sewage (Cardonha et al., 2004; Vieira et al., 2002). This seems to be a common situation, since in storm drain 1, in an earlier study, Escherichia coli concentrations of the same magnitude were detected (data not shown). Therefore, we consider that mitigation of the high FC levels in Jatiúca Beach should start by solving the sewage contamination in this storm drain. This would require a joint effort of the company that manages the sanitary sewer system and municipality that manages the storm water system.

However, the high FC levels found in Jatiúca Beach between September and December 2012 cannot be explained only by influence of storm drain 1 , since this period is characteristically dry and 2012 was a year drier than normal. To further assess other potential causes for the observed high levels of $\mathrm{FC}$, the results were categorized according to tide range and tide stage at the moment of sampling.

\section{Categorization of results according to tide range and tide stage}

The calculated geometric means and confidence intervals (95\%) after categorization of FC concentrations for tide range (spring/neap) and stage (high/low) at the moment of sampling are shown in Figure 5 for monitoring stations PTV, JTC-S, JTC, JTC-N and CRA-1.

During spring tides the range between low and high tide is higher than during neap tides, promoting higher hy- draulic dynamics in coastal waters and having greater potential to dilute contamination from point sources such as sewage-contaminated storm drains and sewer outfalls (Boehm et al., 2002). The three monitoring stations in Jatiúca Beach (JTC S, JTC and JTC N) showed higher FC geometric means in spring tides than in neap tides. The point JTC $\mathrm{N}$ presented a FC geometric mean over 1,000 MPN/100 mL during spring tides. This same pattern was not observed in the surrounding stations of Ponta Verde Cruz das Almas. In Jatiúca Beach, where the main source appears to be a point source (storm drain 1), it was expected that the highest means should be observed during neap tides, when there is less dilution of contamination from storm drain 1. Therefore, results indicate that there must be another source of contamination, probably non-point source, at work in that region.

It has been shown that tide stage can influence concentrations of fecal indicator bacteria (Boehm and Weisberg, 2005). In this study, we observed higher FC geometric means during high tides (except for PTV station). This finding is consistent with other studies conducted in different localities. Wright et al. (2011) and Abdelzaher et al. (2010) also observed higher concentrations of fecal indicators during high tides, and Boehm et al. (2003) found the highest concentrations during ebb tides (immediately after high tide).

Based on the results of tide categorization, we formulated two hypotheses that could explain the high levels of 

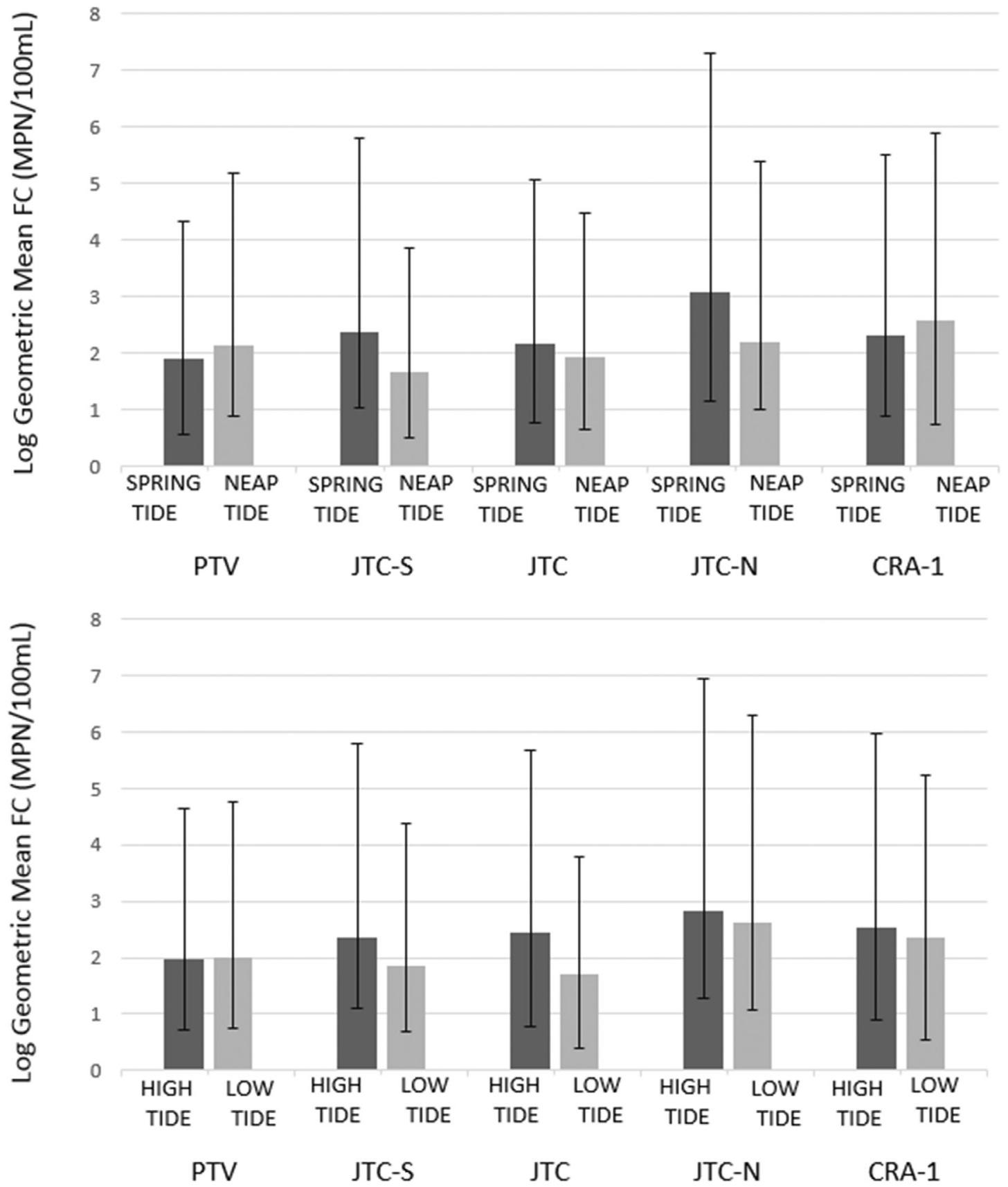

Figure 5 - Geometric means (log scale) and confidence intervals (95\%) after categorization of FC concentrations for tide range (spring/neap - upper chart) and stage (high/low - lower chart) at the moment of sampling for monitoring stations PTV, JTC-S, JTC, JTC-N and CRA-1. Each chart summarizes 85 FC concentration analyses between August and December 2012.

FC found in Jatiúca Beach. The first hypothesis is the contamination of the aquifer near the shoreline. At high tides during spring tides, seawater penetrates deeper into the aquifer and this contamination can be brought back to the water column. Indeed, studies have shown that fecal indicator organisms are not significantly filtered by subsurface sand (Boehm et al., 2004).
We conducted a field survey to identify if buildings close to monitoring station JTC N were connected to the sewer system. Many buildings in the area precede the establishment of a sewer system, having individual septic systems that should be discontinued when sewer trunks were available. However, in the two closest blocks from JTC N monitoring station, we observed two buildings (34 apartments in total), a hostel (40 apartments), two shops and a 
mall (24 shops, two restaurants and a bar) that still do not have connection to the sewer system. Cahoon et al. (2006) determined malfunctioning septic systems as the primary source of water contamination in an estuarine zone in North Carolina. In the same manner, aquifer contamination at Jatiúca could result from malfunctioning septic systems. Aquifer contamination could also be caused by leaks in a sewer trunk line. This hypothesis was proposed by Boehm et al. (2003) to explain high concentrations of fecal indicators in groundwater found at a beach in California. We recommend conducting a detailed investigation of groundwater quality at Jatiúca Beach, as well as inspections on the sewer trunk line and septic systems in the region to confirm or refute this hypothesis.

The second hypothesis, proposed to explain the high FC levels at Jatiúca Beach observed even during dry periods, is the presence of high concentrations of FC in its beach sand. There is evidence showing that fecal microorganisms are able to survive and multiply in soils and sediments of tropical beaches (Byappanahalli and Fujioka, 1998). Phillips et al. (2011) observed a correlation between the concentrations of microorganisms in sand and water, in a study conducted in eight different beaches in Florida, USA, and suggested that the sand is the predominant reservoir of fecal microorganisms that impact water quality. To assess this hypothesis, a detailed investigation of the quality of the sand of Jatiúca Beach is needed.

Wright et al. (2011) conducted a study to assess the sources of high levels of enterococci in a subtropical beach. They monitored storm drain water quality and also beach sand quality along a transect perpendicular to shoreline. In addition to high levels of enterococci found in coastal discharges, the authors observed that the concentration of enterococci decreases as it moves away from the inter-tidal zone, both in sea and continent direction, concluding that the source of enterococci in the studied beach was within the intertidal-zone. Thus, coastal discharges and tide washing of the sand can play a major role in controlling the levels of fecal indicators in the water column.

We believe that the best explanation for the causes of high FC levels in Jatiúca Beach is very similar to the findings of Wright et al. (2011). Our results indicate that the influence of storm drain 1 is the primary source of FC to the water column. When this point source is inactive (when there's no rainfall) high FC levels can arise from tide washing of contaminated sand, which explains the higher FC geometric means observed during high tides and spring tides.

The systematic assessment of quality of coastal waters is used to classify them in relation to bathing conditions. However, to ensure public health protection, it is necessary to find and mitigate the causes of the high levels of contamination often found in urban coastal areas. In this study, we initiated an assessment of the causes of high FC levels in an urban coastal environment in a tropical region, and proposed two hypotheses which will be further investigated in future research.

This study, similar to others (Cardonha et al., 2004; Vieira et al., 2002), exposes the deficiencies in sanitation of an important city in northeastern Brazil. All these cities have tourism as a major contributor in their economies. Those who manage to assure good water quality to their beaches will be at a privileged position, bringing benefits to the health of its citizens and to the performance of the local economy.

\section{Acknowledgments}

The authors thank Regina Lucia Pinheiro de Carvalho and Ricardo César de Oliveira from the environmental state agency (Instituto do Meio Ambiente do Estado de Alagoas - IMA) for their help in obtaining information and extremely important data for this work, and Carlos Davino for assistance in the statistical treatment of the data.

\section{References}

Abdelzaher AM, Wright ME, Ortega C et al. (2010) Presence of pathogens and indicator microbes at a non-point source subtropical recreational marine beach. Appl Environ Microbiol 76:724-732.

Boehm AB, Weisberg SB (2005) Tidal forcing of enterococci at marine recreational beaches at fortnightly and semidiurnal frequencies. Environ Sci Technol 39:5575-5583.

Boehm AB, Fuhrman JA, Mrse RD et al. (2003) Tiered approach for identification of a human fecal pollution source at a recreational beach: Case study at Avalon Bay, Catalina Island, California. Environ Sci Technol 37:673-680.

Boehm AB, Grant SB, Kim JH et al. (2002). Decadal and shorter period variability of surf zone water quality at Huntington Beach, California. Environ Sci Technol 36:3885-3892.

Boehm AB, Shellenbarger GG, Paytan A (2004) Groundwater discharge: Potential association with fecal indicator bacteria in the surf zone. Environ Sci Technol 38:3558-3566.

Byappanahalli MN, Fujioka RS (1998) Evidence that tropical soil environment can support the growth of Escherichia coli. Water Sci Technol 38:171-174.

Cahoon LB, Hales JC, Carey ES et al. (2006) Shellfishing closures in southwest Brunswick County, North Carolina: Septic tanks $v s$. storm-water runoff as fecal coliform sources. J Coastal Res 22:319-327.

Cardonha AMS, Vieira RH, Rodrigues DP et al. (2004) Fecal pollution in water from storm sewers and adjacent seashores in Natal, Rio Grande do Norte, Brazil. Int Microbiol 7:213218.

Edge TA, Boehm AB (2011) Classical and molecular methods to measure fecal bacteria. In: Sadowsky MJ, Whitman RL (eds) The Fecal Bacteria. ASM Press, Washington D.C. pp 241-273.

Phillips MC, Solo-Gabriele HM, Piggot AM et al. (2011) Relationships between sand and water quality at recreational beaches. Water Res 45:6763-6769. 
Shuval H (2003) Estimating the global burden of thalassogenic diseases: Human infectious diseases caused by wastewater pollution of the marine environment. J Water Health 2:5364.

Vieira RH, Catter KM, Saker-Sampaio S et al. (2002) The stormwater drain system as a pollution vector of the seashore in Fortaleza (Ceará State, Brazil). Braz J Microbiol 33:294298.
Wright ME, Abdelzaher AM, Solo-Gabriele HM et al. (2011) The inter-tidal zone is the pathway of input of enterococci to a subtropical recreational marine beach. Water Sci Technol 63:542-549.

Associate Editor: Lara Durães Sette

All the content of the journal, except where otherwise noted, is licensed under a Creative Commons License CC BY-NC. 